\title{
Condition Dependent and Infection Dependent Mate Preferences in Women: Preferences for Healthy Appearing Men are Associated with General Condition and Measures of Infection
}

\author{
Anthony C. Little ${ }^{1 *}$ \\ ${ }^{1}$ Universityof Stirling \\ *Corresponding author (Email: anthony.little@stir.ac.uk) \\ Citation - Little, A. C. (2014). Condition dependent and infection dependent mate preferences in women: \\ Preferences for healthy appearing men are associated with general condition and measures of infection. Animal \\ Behavior and Cognition, 1(3), 423-433. doi: 10.12966/abc.08.14.2014
}

\begin{abstract}
Condition dependent mate choice in females, whereby condition or attractiveness influences preferences for markers of male quality, is seen both in non-humans and humans. There are several possible explanations for such effects. For example, in previous studies of fish it has been postulated that females in poor condition have energetic constraints limiting their choosiness. In this article, preferences for healthy facial appearance were measured in women and related to measures of condition. Questions were associated with two factors: a factor reflecting general health and condition (related to self-ratings of attractiveness, health, and physical fitness) and a factor reflecting experience of and current state of infection (colds per year and current cold). General health and condition were positively related to preferences for healthy appearance in male faces, in line with previously seen condition dependent preferences. However, the measure of current and previous infection was also positively related to preferences for healthy appearance in male faces. While these two findings appear to conflict, in fact, they may reflect different mechanisms at work. Previous explanations, such as competitiveness for mates and/or energetic constraints may explain general condition dependent preferences. In terms of avoiding contagion, however, those most at risk may benefit most from increased attraction to healthy partners: "infection dependent" mate preferences. In this way, general condition may be positively related to preferences for male quality but infection or experience of infection, while associated with a lowering of condition, may also be positively associated with preferences for male quality.
\end{abstract}

Keywords - Face preference, Health, Condition dependent, Contagion, Evolution

One potential source of individual differences in mate preferences and mate choice is the quality, or attractiveness, of the phenotype that an individual finds themselves inhabiting. Quality has been found to influence the expression of physical traits linked to sexual selection (Blumstein, 1998; Hedrick, 2005; Schneider, Fletcher, Shaw, \& Renfree, 2010) and so we might expect quality to impact on mate preference. Indeed, there is evidence for condition dependent mate preferences and choice in non-human animals (e.g., Bakker, Künzler, \& Mazzi, 1999; Evans \& Goldsmith, 2000) and in humans (e.g., Little, Burt, Penton-Voak, \& Perrett, 2001; Penton-Voak, et al., 2003; Vukovic, et al., 2010). There are several potential mechanisms via which condition and attractiveness could impact on preferences and mate choice.

One possible genetic explanation for condition dependent mate choice is that, for example, those who are the daughters of males who lack good-gene markers do not inherit a preference for such markers 
because the genes linked to condition, genes that develop the markers in males and genes that determine the preference in females, are closely linked on the genome. In this way, daughters of high quality fathers are likely to inherit genes for good condition, genes for preferences for good-genes markers, and genes that lead to the development of good-gene markers (at least in males), linking condition and preference (Bakker et al., 1999). Energetic costs may also play a role in condition dependent mate-choice. Because mate search and choice carries an energy cost, those individuals in better condition may better afford this cost and so inspect more potential mates in order to maximize mate quality and hence likely set a higher threshold of minimal attractiveness acceptable in a mate (Lopez, 1999). In general it might be expected that low quality females may be least likely to have energy to spare for mate-choice and so energetic cost to choice is a plausible explanation for condition dependent preferences. Low condition individuals may simply be unable to be choosy due to the physiological costs involved in making choices. Another potential mechanism involves a behavioral response to own condition or attractiveness, as condition influences competitiveness for mates and thus impacts mating strategy. It is potentially adaptive for females of low mate-value in order to avoid the costs of decreased parental investment/potential desertion from high quality partners (Little et al., 2001). Such reasoning arises from notions that high-quality males are least likely to invest in or even desert their partners (Gangestad \& Simpson, 2000). High quality females are most likely to be able to extract investment from high-quality partners. In this way, the matevalue of a woman may determine her preferences for quality due to differing costs and benefits of mating with high quality males between females of different mate-values. In this view, condition, quality, and attractiveness are all terms that relate to an individual's mate-value, or, perhaps more descriptively, market-value.

Evidence for condition dependent preferences and choice has been observed in several nonhuman animal species. Milinski and Bakker (1990) have shown that in three-spined sticklebacks (Gasterosteus aculeatus) parasites reduce the intensity of the red coloration around males' throats. Bakker et al. (1999) allowed female three-spined sticklebacks to choose between computer animations of courting males representing an "attractive" versus "unattractive" phenotype. Females who were in better condition showed a greater preference for the red-throated male and those in worse condition showed a preference for the orange male. Further, for symmetry, a trait which has long been associated with quality, female sticklebacks in poor physical condition do not show as strong a preference for symmetry as those in better condition (Mazzi, Künzler, \& Bakker, 2003). Another example of condition dependent mate choice comes from guppies. The parasite Gyrodactylus turnbulli reduces the sexual display and color intensity of male guppies (Poecilia reticulata), which makes them less attractive to females (Houde \& Torio, 1992). Lopez (1999) examined how this same parasite influences female mate choice decisions. When presented with two males, uninfected females were significantly more likely to choose the attractive male over the less attractive male. By contrast, infected females were less discriminative in their choice of mates and showed no preference for the more attractive male over the less attractive male. In the same study, activity during choice trials also decreased with increasing parasite load suggesting that infected females were unable to engage in energetically costly behavior related to choice, such as inspection (Lopez, 1999).

Beyond fish species, condition dependent choice is also seen in amphibians and birds. For example, in spadefoot toads (Pelobates fuscus), males in better condition produce longer calls (Pfennig \& Tinsley, 2002). Parasitized females do not show a preference for male call length whereas unparasitized females prefer longer calls which are indicative of a male in good condition (Pfennig \& Tinsley, 2002). In birds, zebra finches (Taeniopygia guttata) provide an interesting example of flexibility in mating strategy according to relative attractiveness. Females made attractive with colored leg bands were found to spend less time carrying out parental duties than both those typical of their sex and unattractive females but still had higher reproductive success, possibly because mates of attractive females spent more time than those typical of their sex carrying out parental duties (Burley, 1986). Further, experimental manipulation of female quality, via rearing in small or large broods, has shown that high-quality females prefer high-quality males' songs, while low-quality females prefer low-quality males' song (Kokko \& Heubel, 2008). 
Inspired by work on non-human animals, researchers have also examined possible condition dependent preferences in humans. In humans, several studies have examined preferences for face traits such as symmetry or masculinity/femininity, traits that are proposed to indicate mate quality (e.g., see Little, Jones, \& DeBruine, 2011 for review). For example, Little et al. (2001) found that women who thought they were physically attractive preferred more masculine faces and had greater preferences for symmetry than those women who thought they were less physically attractive. Such condition dependent preferences have also been shown for more objective cues of attractiveness, such as other rated facial attractiveness and measured waist-to-hip ratio (Penton-Voak et al., 2003; Smith et al., 2009). More attractive/feminine women prefer more masculine faced men than less attractive/feminine women.

Similar findings have been found for preferences for facial health. Condition can encompass physical (e.g., health) and psychological factors (e.g., stress, anxiety, and depression). Jones et al. (2005) found that women with low (attractive and healthy) waist-to-hip ratios or who scored low on psychological stress measures expressed greater attraction to healthy male faces than did women with relatively high waist-to-hip ratios or who scored relatively high on psychological health measures. Further, examining the role of behavioral quality influencing preferences in men, Jones et al. (2007) have shown that men scoring high on sensation seeking, men who possess good physical condition and so can afford to pursue high-risk activities, demonstrated stronger preferences for female face femininity than their peers who exhibited less risk-taking behavior. Beyond faces, analogous findings are seen in women's preferences for masculine male voices. In humans, fundamental frequency (an acoustic correlate of voice pitch) is sexually dimorphic, with men displaying lower voice pitch than women, and women tend to prefer men's voices with low pitch (Feinberg, Jones, Little, Burt, \& Perrett, 2005). As in faces, self-rated attractiveness is positively related to women's preferences for masculinized men's voices (voices with lower pitch) (Vukovic et al., 2010). Finally, again examining face preferences, Little \& Mannion (2006) found that viewing highly attractive women decreased women's self-rated attractiveness and also found that masculinity preferences were stronger after viewing unattractive women than after viewing attractive women. This latter finding suggests that it is women's subjective impressions of their own market-value (i.e., their self-rated attractiveness) that are particularly important for these individual differences in masculinity preferences (Little \& Mannion, 2006).

There is good evidence that condition impacts mate preferences, with females in better condition demonstrating stronger preferences for cues to male quality. One gap between studies of non-human animals and humans, however, lies in assessing health measures. Work on humans has generally focused on cues to attractiveness (although not exclusively), whereas in non-human animals the effects of current parasitization have also been found to affect preference (Lopez, 1999; Pfennig \& Tinsley, 2002). While parasitization is somewhat more difficult to study in humans, it is possible to examine infection and infection rates because there is a type of virus that almost everyone commonly experiences: the common cold. Given parasites are associated with lower levels of preferences for quality in non-human animals it could be predicted that infection with cold and experience of more colds would be associated with lower preferences for male quality in women. Such a difference in preference could come about via the energetic constraints put forward to explain condition dependent preferences when studying parasitized fish (Lopez, 1999). In contrast to expectations from a condition dependent view, those who are infected and who are most likely to become infected would likely benefit most from avoiding infectious others. This would lead to the opposite prediction: infection with cold and experience of more colds would be associated with higher preferences for male quality in women. Such a difference in preference could come about via the notion of the behavioral immune system by which individuals who have recently been ill displayed heightened attention to and avoidance of other individuals who may display cues to contagion (Miller \& Maner, 2011). In line with this view of preferences for health being higher in association with health risks, in cross-cultural studies, pathogen prevalence has been found to be positively related to the importance placed on physical beauty (Gangestad \& Buss, 1993; Gangestad, Haselton, \& Buss, 2006) and the attractiveness of masculine male faces to women (DeBruine, Jones, Crawford, Welling, \& Little, 2010). To test these predictions, women's preferences for healthy appearing male and female faces were measured. These preferences were related to questions associated with general condition (face and body 
attractiveness, medical health, fitness, good diet) and instances of infection (colds per year and current cold status).

\section{Method}

\section{Participants}

Participants were 147 heterosexual women (aged 18-60, $M=31.3, S D=10.8$ ). Participants were volunteers who were recruited via a dedicated research website.

\section{Healthy and unhealthy appearing face stimuli}

Original images were 50 Caucasian young adult male and 50 Caucasian young adult female photographs taken under standard lighting conditions and with a neutral expression. These images were rated for "How healthy does this person appear?" on a 1 to 7 scale $(1=$ low, $7=$ high $)$ by 10 raters $(8$ women, 2 men $\left(M_{\text {age }}=24.3, S D=6.0\right)$. Images were presented in a random order and there was no time limit for the rating. From these scores, an average health rating was computed for each face. Ratings showed good reliability across raters (Cronbach's Alpha $=0.77$ ).

Separately for male and female images, the 15 top and 15 bottom scoring images were selected. A composite image possessing the average shape and color of each set of 15 faces was created. For every image, 174 feature points were delineated on each face image. Composite images were created by warping, and then superimposing all of the images in each group into the relevant average face shape (Benson \& Perrett, 1993). All images were made perfectly symmetrical by combining them with their mirror image prior to manipulation. Mean health rating scores of the four face sets were: female low perceived health $=2.83$, female high perceived health $=4.53$, male low perceived health $=2.87$, male high perceived health $=4.30$.

The faces used in the preference tests were 10 transformed pairs ( 5 male and 5 female) of composite images (made from combining two images) with one of the pair being made more healthy in appearance and the other less healthy (see Figure 1 for example images). The 10 composite images were made by creating an average image made up of 2 randomly assigned individual facial photographs drawn from the face sample noted above (this technique has been used to create composite images in previous studies, (e.g., Benson \& Perrett, 1993; Little \& Hancock, 2002; Tiddeman, Burt, \& Perrett, 2001). Faces were transformed on a health dimension using the difference between the high perceived health and low perceived health composites outlined above (Perrett et al., 1998). Transforms represented 50\% \pm the difference in shape and color between these two composites. 

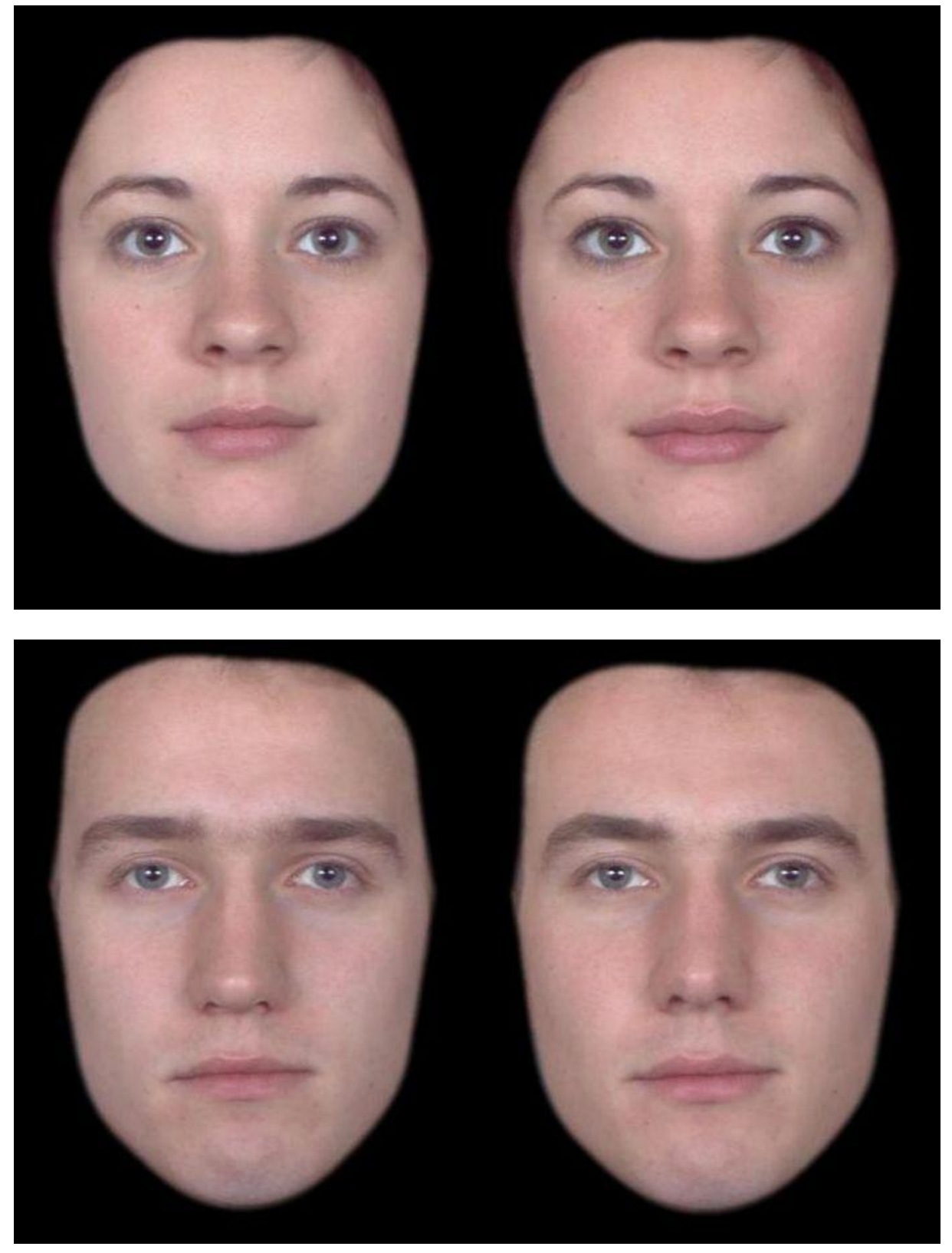

Figure 1. Examples of less healthy (left) and more healthy (right) appearing female and male images. 


\section{Questions}

Questions addressed age in years and sexuality (heterosexual, bisexual, homosexual). Self-ratings of various measures were collected using a 7-point Likert scale. Measures were:

"Please rate your..."

Facial attractiveness (anchored 1 "unattractive," 7 "very attractive")

Body attractiveness (anchored 1 "unattractive," 7 "very attractive")

General medical health (anchored 1 "very unhealthy," 7 "very healthy")

Athletic fitness (anchored 1 "very unfit," 7 "very fit")

Other questions were:

How healthy is your present diet? (e.g., how low in fat and high in fresh fruit and vegetables) (anchored 1 "very unhealthy," 7 "very healthy")

How many times a year would you suffer from a cold/cough? (options were: never, 1-2 times a year, 3-4 times a year, 5-6 times a year, 7-8 times a year, 9-10 times a year, 11+ times a year. Options formed a scale from $0-6$ )

Are you at present suffering from a cold? (options were: yes and no) 21 participants reported having a cold at time of testing.

\section{Procedure}

After following the link to participate, participants were administered the questionnaire as noted above. After the questions were completed, participants proceeded to the face preference task. The 10 pairs of composite images were presented with order and side of presentation randomized. Images remained on screen until an image was selected as "most attractive" and there was no time limit for judgments. Selecting an image moved the participant onto the next trial.

\section{Results}

Preference for healthy appearing male and female faces was computed as a \% of the healthy appearing images chosen from the pairs. A Pearson product moment correlation demonstrated that preferences for healthy appearance in male and female faces were positively related $(\mathrm{r}=0.268, p=$ $0.001)$. To assess overall preferences for health, one-sample t-tests against chance preference (50\%) were conducted. These revealed significant preferences for healthy appearance in female $(\mathrm{t}(146)=25.66, p<$ $0.001)$ and male $(\mathrm{t}(146)=10.88, p<0.001)$ faces. Scores can be seen in Figure 2.

Note that below, all variables are self-rated and so should correctly be labeled, for example, selfrated facial attractiveness, self-rated body attractiveness etc. To save repetition, however, self-rated has been omitted.

Initially, Pearson product moment correlation coefficients were calculated to examine the relationship between preferences for healthy appearance and the other measures. For female faces, age was positively related $(\mathrm{r}=0.182, p=0.028)$ and facial attractiveness was negatively related $(\mathrm{r}=-0.186, p$ $=0.024)$ to healthy appearance preferences. Body attractiveness $(\mathrm{r}=0.002, p=0.983)$, fitness $(\mathrm{r}=-0.105$, $p=0.207)$, health $(\mathrm{r}=0.056, p=0.500)$, diet quality $(\mathrm{r}=0.017, p=0.836)$, numbers of colds per year $(\mathrm{r}=$ $-0.003, p=0.975)$, and cold now $(\mathrm{r}=0.029, p=0.726)$ were not significantly related to healthy appearance preferences in female faces. 


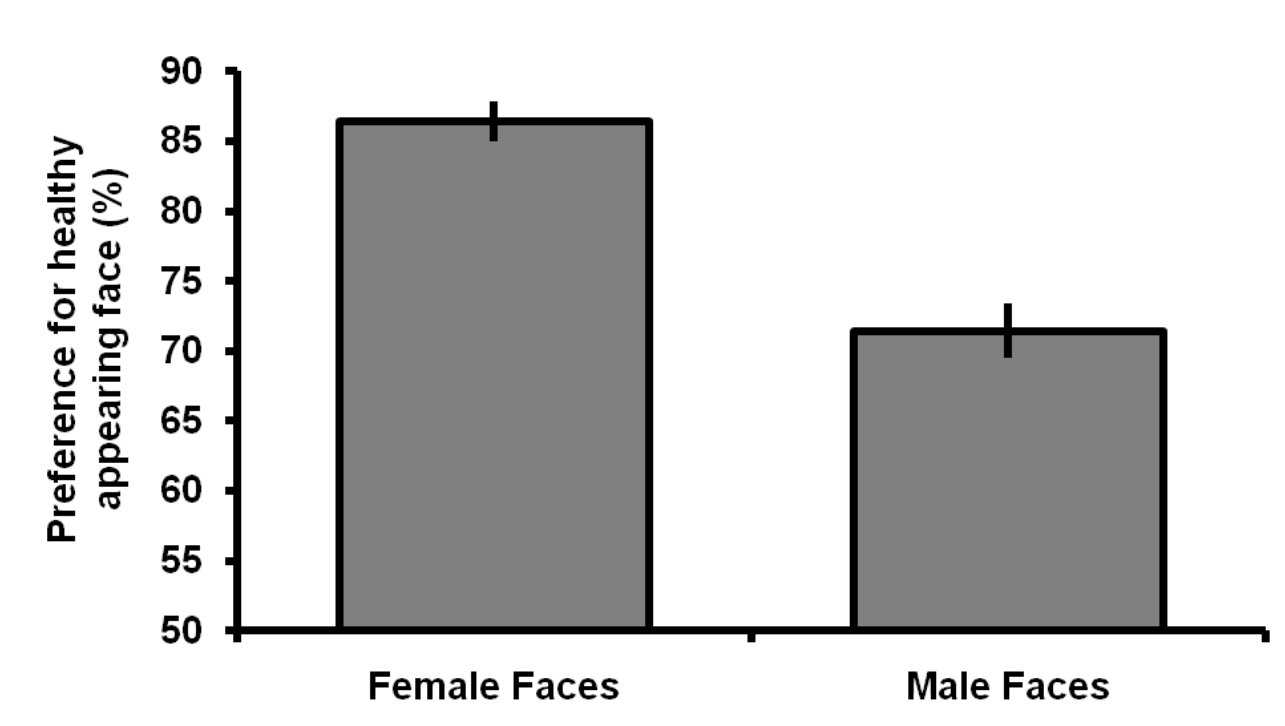

Figure 2. Preferences for healthy appearance in female faces (top) and male faces (bottom) ( \pm 1 SEM).

For male faces, facial attractiveness $(\mathrm{r}=0.174 p=0.035)$, health $(\mathrm{r}=0.177, p=0.032)$, and cold now $(\mathrm{r}=0.196, p=0.017)$ were positively related to healthy appearance preferences. Fitness $(\mathrm{r}=0.145, p$ $=0.079)$ and numbers of colds per year $(\mathrm{r}=0.159, p=0.055)$ were positively but not significantly related to healthy appearance preferences, although effects were close to significance. Age $(\mathrm{r}=0.030, p=0.721)$, body attractiveness $(\mathrm{r}=0.016, p=0.849)$, and diet quality $(\mathrm{r}=0.124, p=0.134)$ were not significantly related to healthy appearance preferences in male faces.

Because of the binary nature of the variable, and to further assess the effects of having a current cold on preference for healthy appearance in male faces, a univariate ANOVA was conducted with preference for healthy appearance in male faces as the dependent variable and having a cold as a betweenparticipant variable. This revealed a significant effect of having a cold $\left(\mathrm{F}_{1,145}=5.80, p=0.017\right.$, note that this is equivalent to the correlation above). It is possible that having a cold simply reflects the general probability of catching a cold. To examine if having a cold was an independent predictor of health preference, number of colds per year was controlled for. Repeating the ANOVA and entering age and number of colds per year as covariates again revealed the effect of having a cold remained while controlling for these variables $\left(\mathrm{F}_{1,143}=4.46, p=0.037\right)$. Preferences for those with and without a current cold can be seen in Figure 2.

The initial analysis represented a large volume of correlations involving several measures that are likely to be interrelated. In order to examine these interrelations, principal component factor analysis with varimax rotation was conducted on the various measures. This generated two factors and the loadings of each question can be seen in Table 1. Factor 1 (30.8\% of variance) reflected positive self-ratings of attractiveness, health, fitness, and diet. Factor 2 (19.5\% of variance) reflected a higher number of colds per year and chance of having a current cold.

Scores for each factor were saved for each participant and correlated with healthy appearance preferences. For female faces, Factor $1(\mathrm{r}=-0.064 p=0.443)$ and Factor $2(\mathrm{r}=0.009 p=0.914)$ were not significantly related to preferences for healthy appearance. For male faces, Factor $1(\mathrm{r}=0.186 p=0.024)$ and Factor $2(r=0.199 p=0.016)$ were both significantly positively related to preferences for healthy appearance. 


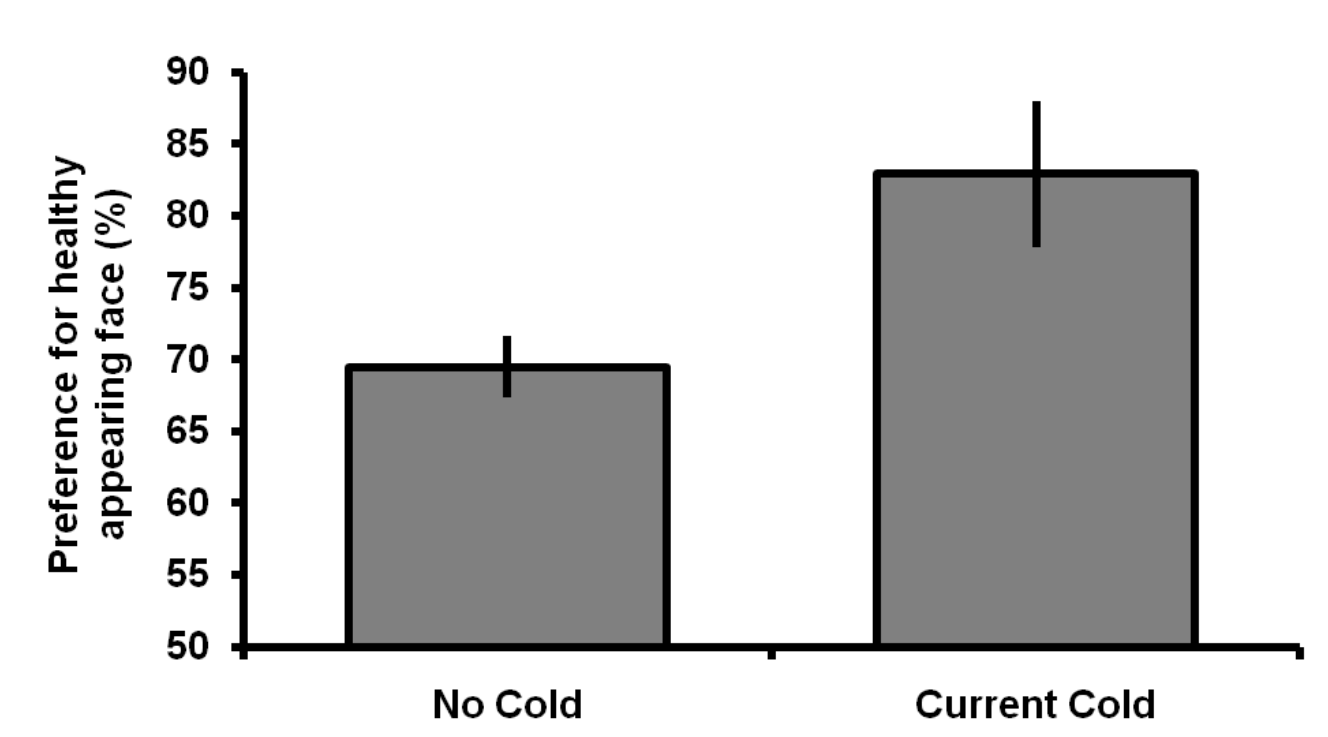

Figure 3. Preferences for healthy appearance in male faces according to current cold status $( \pm 1$ SEM).

Table 1

Factor Loadings for Each Question in the Principle Component Analysis with Varimax Rotation

\begin{tabular}{lcc}
\hline & \multicolumn{2}{c}{ Factor } \\
\hline Face attractiveness & 1 & 2 \\
Body attractiveness & $\mathbf{0 . 5 1 1}$ & 0.001 \\
Health & $\mathbf{0 . 7 2 3}$ & 0.057 \\
Number of colds & $\mathbf{0 . 4 9 3}$ & 0.076 \\
Cold now & -0.025 & $\mathbf{0 . 7 3 6}$ \\
Fitness & 0.091 & $\mathbf{0 . 8 4 4}$ \\
Diet Quality & $\mathbf{0 . 8 1 6}$ & 0.096 \\
\hline
\end{tabular}

\section{Discussion}

In line with previous work (Jones, Little, Burt, \& Perrett, 2004), women preferred more healthy appearing male and female faces. The findings of the current study also broadly support previous work on condition dependent preferences in humans (e.g., Little et al., 2001; Penton-Voak et al., 2003; Vukovic et al., 2010). Examining individual associations, self-rated facial attractiveness, health, and fitness were all positively related to preferences for healthy appearing male faces, although fitness was not significantly so. Indeed, when entered into a principal component analysis these questions, and others related to general condition (body attractiveness and diet quality), were all found to be interrelated. Measures of infection with the common cold were also taken and, in contrast to the expectation that individuals in better condition would prefer signs of quality most strongly, those suffering from a cold or who reported having more colds over the past year had stronger preferences for healthy appearing male faces. Interestingly, and perhaps unexpectedly also, infection questions related to an orthogonal factor to the general condition questions. When combined in this factor, infection was positively related to preferences 
for healthy appearance in male faces. There was also an independent effect of having cold, whereby the effect of having a cold on health appearance preference remained when controlling for the number of colds in year. Notably, in examining the factors, preferences for healthy appearance in female faces was unrelated to measures of general condition or measures of infection. Specificity of the effects seen here to male faces suggests such effects are most relevant to mate choice and not to general preferences, which again may be surprising considering that infection is relevant whether dealing with opposite-sex or samesex individuals.

As noted, in non-human animals the effects of current parasitization have been found to affect preference whereby parasitized individuals show weaker preferences for cues to male quality (Lopez, 1999; Pfennig \& Tinsley, 2002). The results for colds seen here show the opposite pattern: those with a cold or more experience of colds show stronger preferences for healthy male facial appearance. Of course exact comparison of particular parasites between humans and non-human animals is extremely difficult. There could be differences between the parasites observed in other studies and the common cold measured here that account for the difference. Indeed, the common cold does not have particularly debilitating effects and the impact of infection on the infected individual may be an important variable in regards to how infection may influence preferences. On the other hand, we might expect some comparability given that parasites and the common cold are transmitted from infectious conspecifics and that both place an energetic burden on the infected organism. While this pattern in humans may appear puzzling from a condition dependent viewpoint, the results align with recent studies on the behavioral immune system in humans. Recent studies have shown that individuals who have recently been ill display heightened attention to and avoidance of other individuals who may display cues to contagion (Miller \& Maner, 2011). Likewise, individuals who feel, or are primed to feel, more vulnerable to disease show heighted sensitivity to cues to contagion in other people such that, for example, perceived disease vulnerability leads to better recognition of individuals displaying disease cues (Miller \& Maner, 2012). Perhaps in humans, the behavioral immune system leads those who perceive the greatest risk of infection to develop preferences that help avoid unhealthy partners from which infection may be transmitted.

Given the different patterns of results for general condition measures and infection measures, two different mechanisms may be at work. The first mechanism may reflect genetic, energetic, or marketvalue explanations of condition dependent preferences. In other words, individuals in good condition, for example, may be best able to pay the cost of energetic mate choice (although this is unlikely to play a large role in our simple preference test here) and/or also may be more competitive and attracting and keeping high quality partners because of their high market value (Little \& Mannion, 2006). An additional mechanism may be at play, at least in humans, related to the behavioral immune system (Miller \& Maner, 2011), whereby experience of infection leads individuals to avoid unhealthy appearing partners. This mechanism may reflect "infection dependent," or perhaps "infection-risk dependent," mate preferences, a complementary phenomenon to condition dependent mate preferences. This second mechanism is consistent with studies showing heightened preferences for healthy appearance under conditions of higher pathogen prevalence. For example, one study, examining a cross-cultural sample of 30 countries, found that poorer health (i.e., higher mortality and incidence of disease) was related to stronger female preferences for male masculinity (DeBruine et al., 2010). Similarly, measures of childhood illness have been found to be positively related to preferences for exaggerated sex-typical (masculine in male faces, feminine in female faces) characteristics in opposite-sex faces (de Barra, DeBruine, Jones, Mahmud, \& Curtis, 2013). Indeed, visual exposure to cues of pathogens has been found to increase preferences for exaggerated sex-typical and symmetric faces opposite-sex faces (Little, DeBruine, \& Jones, 2011). Together, the results here, and the findings of previous research, suggest that cues to the prevalence of, experience with (which may reflect either prevalence or susceptibility), or actual infection with pathogens can lead to heightened attraction to health in faces. It is interesting to note that specificity to preferences in opposite-sex faces, as seen in the current study, is also a feature of previous research findings (de Barra et al., 2013; Little, DeBruine et al., 2011).

There are limitations to the findings here. Here measures are self-reports and prone to memory biases or likely to be more subjective that other measures. For example, it would be useful to have more 
accurate measures of colds and more objective measures of health and attractiveness. Additionally, the sample of individuals with a current cold was relatively small $(n=21)$ and the test was conducted between-participants. It would of course be valuable to replicate the effects seen here in a larger, withinparticipant sample. In future research, it would also be interesting to examine aspects of the behavioral immune system in non-human animals. The results here suggest a contrast with previous work in fish species. Potentially, fish species may lack aspects of what has been termed the behavioral immune system in humans. Perhaps our primate cousins may be more likely to show similar effects to humans in terms of their behavioral responses to infection risks than other non-human species.

In summary, women's general health and condition were positively related to preferences for healthy appearance in male faces, in line with previously seen condition dependent preferences. However, current and previous infection was also positively related to preferences for healthy appearance in male faces. While these two findings appear to conflict, in fact, they may reflect different mechanisms at work. Previous explanations, such as competitiveness for mates and/or energetic constraints may explain general condition dependent preferences. In terms of avoiding contagion, however, those most at risk may benefit most from increased attraction to healthy partners: "infection dependent" or "infection-risk dependent" mate preferences, a complementary phenomenon to condition dependent mate preferences. In this way, general condition may be positively related to preferences for male quality but infection or experience of infection, while associated with a lowering of condition, may also be positively associated with preferences for partner health and partner quality.

\section{References}

Bakker, T. C. M., Künzler, R., \& Mazzi, D. (1999). Condition-related mate-choice in sticklebacks. Nature, $401,234$. Benson, P. J., \& Perrett, D. I. (1993). Extracting prototypical facial images from exemplars. Perception, 22, 257262.

Blumstein, D. T. (1998). Female preferences and effective population size. Animal Conservation, 1, $173-177$.

Burley, N. (1986). Sexual selection for aesthetic traits in species with biparental care. American Naturalist, 127, 415-445.

de Barra, M., DeBruine, L. M., Jones, B. C., Mahmud, Z. H., \& Curtis, V. A. (2013). Illness in childhood predicts face preferences in adulthood. Evolution and Human Behavior, 34, 384-389.

DeBruine, L. M., Jones, B. C., Crawford, J. R., Welling, L. L. M., \& Little, A. C. (2010). The health of a nation predicts their mate preferences: Cross-cultural variation in women's preferences for masculinized male faces. Proceedings of the Royal Society B-Biological Sciences, 277, 2405-2410.

Evans, M. R., \& Goldsmith, A. R. (2000). Male wrens with large testes breed early. Animal Behaviour, 60, $101-105$.

Feinberg, D. R., Jones, B. C., Little, A. C., Burt, D. M., \& Perrett, D. I. (2005). Manipulations of fundamental and formant frequencies influence the attractiveness of human male voices. Animal Behaviour, 69, 561-568.

Gangestad, S. W., \& Buss, D. M. (1993). Pathogen prevalence and human mate preferences. Ethology and Sociobiology, 14, 89-96.

Gangestad, S. W., Haselton, M. G., \& Buss, D. M. (2006). Toward an integrative understanding of evoked and transmitted culture: The importance of specialized psychological design. Psychological Inquiry, 17, 138151 .

Gangestad, S. W., \& Simpson, J. A. (2000). The evolution of human mating: Trade-offs and strategic pluralism. Behavioural and Brain Sciences, 23, 573-644.

Hedrick, A. (2005). Environmental condition-dependent effects on a heritable, preferred male trait. Animal Behaviour, 70, 1121-1124.

Houde, A. E., \& Torio, A. J. (1992). Effect of parasitic infection on male colour pattern and female choice in guppies. Behavioural Ecology, 3, 346-351.

Jones, B. C., DeBruine, L. M., Little, A. C., Conway, C. A., Welling, L. L. M., \& Smith, F. (2007). Sensation seeking and men's face preferences. Evolution and Human Behavior, 28, 439-446.

Jones, B. C., Little, A. C., Boothroyd, L., Feinberg, D. R., Cornwell, R. E., DeBruine, L. M. ...Perrett, D. I. (2005). Women's physical and psychological condition independently predict their preference for apparent health in faces. Evolution and Human Behavior, 26, 451-457.

Jones, B. C., Little, A. C., Burt, D. M., \& Perrett, D. I. (2004). When facial attractiveness is only skin deep. Perception, 33, 569-576. 
Kokko, H., \& Heubel, K. (2008). Condition-dependence, genotype-by-environment interactions and the lek paradox. Genetica, 134, 55-62.

Little, A. C., Burt, D. M., Penton-Voak, I. S., \& Perrett, D. I. (2001). Self-perceived attractiveness influences human female preferences for sexual dimorphism and symmetry in male faces. Proceedings of the Royal Society B-Biological Sciences, 268, 39-44.

Little, A. C., DeBruine, L. M., \& Jones, B. C. (2011). Exposure to visual cues of pathogen contagion changes preferences for masculinity and symmetry in opposite-sex faces. Proceedings of the Royal Society BBiological Sciences, 278, 2032-2039.

Little, A. C., \& Hancock, P. J. (2002). The role of masculinity and distinctiveness on the perception of attractiveness in human male faces. British Journal of Psychology, 93, 451-464.

Little, A. C., Jones, B. C., \& DeBruine, L. M. (2011). Facial attractiveness: Evolutionary based research. Philosophical Transactions of the Royal Society B-Biological Sciences, 366, 1638-1659.

Little, A. C., \& Mannion, H. (2006). Viewing attractive or unattractive same-sex individuals changes self-rated attractiveness and face preferences in women. Animal Behaviour, 72, 981-987.

Lopez, S. (1999). Parasitized female guppies do not prefer showy males. Animal Behaviour, 57, 1129-1134.

Mazzi, D., Künzler, R., \& Bakker, T. C. M. (2003). Female preference for symmetry in computer-animated threespined sticklebacks, Gasterosteus aculeatus. Behavioural Ecology and Sociobiology, 54, 156-161.

Milinski, M., \& Bakker, T. C. (1990). Female sticklebacks use male coloration in sticklebacks and therefore avoid parasitised males. Nature, 344, 330-333.

Miller, S. L., \& Maner, J. K. (2011). Sick Body, Vigilant Mind: The Biological Immune System Activates the Behavioral Immune System. Psychological Science, 22, 1467-1471.

Miller, S. L., \& Maner, J. K. (2012). Overperceiving Disease Cues: The Basic Cognition of the Behavioral Immune System. Journal of Personality and Social Psychology, 102, 1198-1213.

Penton-Voak, I. S., Little, A. C., Jones, B. C., Burt, D. M., Tiddeman, B. P., \& Perrett, D. I. (2003). Measures of female condition influence preferences for sexual dimorphism in faces of male Homo sapiens. Journal of Comparative Psychology, 117, 264-271.

Perrett, D. I., Lee, K. J., Penton-Voak, I. S., Rowland, D. R., Yoshikawa, S., Burt, D. M.,...Akamatsu, S. (1998). Effects of sexual dimorphism on facial attractiveness. Nature, 394, 884-887.

Pfennig, K. S., \& Tinsley, R. C. (2002). Different mate preferences by parasitized and unparasitized females potentially reduces sexual selection. Journal of Evolutionary Biology, 15, 399-406.

Schneider, N. Y., Fletcher, T. P., Shaw, G., \& Renfree, M. B. (2010). The effect of pregnant and oestrous females on male testosterone and behaviour in the tammar wallaby. Hormones and Behavior, 58, 378-384.

Smith, F. G., Jones, B. C., Welling, L. L. W., Little, A. C., Vukovic, J., Main, J. C., \& DeBruine, L. M. (2009). Waist-hip ratio predicts women's preferences for masculine male faces, but not perceptions of men's trustworthiness. Personality and Individual Differences, 47, 476-480.

Tiddeman, B. P., Burt, D. M., \& Perrett, D. I. (2001). Prototyping and transforming facial texture for perception research. IEEE Computer Graphics and Applications, 21, 42-50.

Vukovic, J., Jones, B. C., DeBruine, L., Feinberg, D. R., Smith, F. G., Little, A. C., ...Main, J. (2010). Women's own voice pitch predicts their preferences for masculinity in men's voices. Behavioral Ecology, 21, 767-772. 